\title{
Catalytic Mononitration of Phenol using iso-Propyl Nitrate over Zeolite Catalysts
}

\author{
Keith Smith $^{\mathrm{a} *}$. Mansour D. Ajarim ${ }^{\mathrm{a}}$. Gamal A. El-Hitia ${ }^{\mathrm{a}}$ Christelle Peters ${ }^{\mathrm{b}}$ \\ ${ }^{a}$ School of Chemistry, Cardiff University, Main Building, Park Place, Cardiff, CF10 3AT, \\ UK \\ ${ }^{b}$ Department of Chemistry, University of Wales Swansea, Swansea, SA2 8PP, UK \\ e-mail: smithk13@ cardiff.ac.uk; el-hitiga@cardiff.ac.uk
}

\begin{abstract}
Mononitration of phenol was investigated using iso-propyl nitrate as a nitrating agent over various zeolite catalysts under different reaction conditions. Zeolite H $\beta$ with a low $\mathrm{Si} / \mathrm{Al}$ ratio $(12.5)$ was found to be an active catalyst for nitration of phenol under reflux conditions in dichloroethane, producing 2- and 4-nitrophenols in a ratio of around 1:1. However, zeolites H-mordenite, HY and H $\beta$ (with high Si/Al ratio - 150 or 300) gave 2-nitrophenol as the major product (ortho/para ratio $=c a .2-3)$.
\end{abstract}

Key words Nitration. Phenol . Nitrophenols . Zeolite catalysis . H $\beta$. Regioselectivity

\section{$1 \quad$ Introduction}

The synthesis of valuable industrial, pharmaceutical, agrochemical and fine chemicals frequently involves electrophilic aromatic substitution reactions. Indeed, substituted aromatic compounds represent useful intermediates in many synthetic processes. For example, aromatic nitro compounds are versatile chemical feedstocks for a wide range of industrial products, such as pharmaceuticals, agrochemicals, dyestuffs and explosives, and aromatic nitration is one of the most important and widely studied chemical reactions [1,2].

The traditional method of phenol nitration involves the use of a mixture of nitric and sulfuric acids to produce nitrophenols in which the ortho/para ratio decreases from around 
2.1 to around 0.9 as the concentration of sulfuric acid increases [3]. However, the poor selectivity and other disadvantages of this process have stimulated efforts to develop cleaner and more environmentally benign processes. It is well recognised that zeolites and other solid acid catalysts can play an important role in the development of greener organic syntheses through their abilities to act as recyclable heterogeneous catalysts, support reagents, entrain by-products, avoid aqueous work-ups and enhance product selectivities [4-11]. For example, we have shown that zeolites or other solids can have advantages in alkylation [12], acylation [13,14], methanesulfonylation [15], bromination [16], chlorination [17], and nitration [18-22] of aromatic compounds.

Several solid catalytic systems have been developed for the nitration of phenol to nitrophenols. The most popular reagents have been nitric acid and acetyl nitrate and solids used include silica gel [23], metal salt modified clays [24], mixed metal oxides [25], a variety of strongly acidic solids (e.g. heteropolyacids [26], sulfated MCM-41 [27], silica impregnated with sulfuric acid [28] or a hydrogen sulfate salt [29], sulfated titania [30], sulfated mixed metal oxides [31] and zeolite HBEA [32]), and a series of non-acidic or weakly acidic ionexchanged zeolites [33]. The selectivities observed are interesting. With the highly acidic solids ortho-nitrophenol generally predominates to a much greater extent than with a mixture of sulfuric and nitric acids, regardless of the structure of the solid. Even zeolite HBEA gives a very high proportion of the ortho- product, despite the fact that zeolites are normally associated with increased para- selectivities in aromatic substitution reactions. By contrast, different degrees of para-selectivity have been reported with some of the less acidic solids. However, such observations are difficult to interpret since nitric acid is capable of nitrating phenol (albeit in a rather messy fashion) without catalysis by added agents and because the mechanism of nitration is complicated [1,2,34], potentially involving some or all of the following: direct nitration of the ring; addition to Wheland intermediates; elimination of 
nitrous acid from such adducts; nitrosation by any nitrous acid produced; phenyl nitrate as an intermediate; cyclohexadienone intermediates; rearrangement reactions; and oxidation.

In continuation of our interest in aromatic nitration reactions over solid catalysts [1822], we felt it might be useful to investigate the nitration of phenol with a less active nitrating agent that would not react with the substrate in the absence of a catalyst, so that the influence of the catalyst might be more critical. We chose iso-propyl nitrate as the reagent (we are not aware of any previous studies using this reagent for nitration of phenol) and studied a range of acidic zeolites as catalysts. We now disclose the results of these investigations.

\section{Experimental}

\subsection{Materials}

Chemicals and solvents were purchased from Aldrich Chemical Company and used without further purification. Commercial zeolites were purchased from Aldrich Chemical Company or Zeolyst International. All zeolite catalysts were freshly calcined at $550{ }^{\circ} \mathrm{C}$ for a minimum of $6 \mathrm{~h}$ prior to use.

\subsection{Analysis and characterisation of the products}

Product mixtures from the nitration reactions of phenol (Scheme 1) were subjected to gas chromatography on a HEWLETT PACKARD SERIES II 5890 gas chromatograph, fitted with a ZEBRON ZB-5 (5\% phenyl polysiloxane) $30 \mathrm{~m}$ length column. The GC conditions used for analysis were: $60{ }^{\circ} \mathrm{C}$ for $1 \mathrm{~min}$, ramped to $160{ }^{\circ} \mathrm{C}$ at $15^{\circ} \mathrm{C} / \mathrm{min}$ and held for $3 \mathrm{~min}$. The injection temperature was $250{ }^{\circ} \mathrm{C}$ and the detection temperature $300{ }^{\circ} \mathrm{C}$. Tetradecane was used as an internal standard. 
Phenol (1) and iso-propyl nitrate are commercial materials and were used without further purification. iso-Propoxybenzene was characterised by NMR spectroscopy and mass spectrometry.

\subsection{Typical experimental procedure for the nitration of phenol (1) in the presence of an} acidic zeolite catalyst

Quantities are recorded in the footnotes to the appropriate tables or text. All reactions were carried out in a $250 \mathrm{ml}$ round bottomed flask equipped with a water condenser and a magnetic stirrer. In a typical experiment, a mixture of zeolite $\mathrm{H} \beta(\mathrm{Si} / \mathrm{Al}=12.5 ; 2.0 \mathrm{~g})$, isopropyl nitrate $(2.0 \mathrm{~g}, 19.0 \mathrm{mmol})$ and phenol $(\mathbf{1} ; 0.9 \mathrm{~g}, 9.5 \mathrm{mmol})$ in 1,2 dichloroethane (DCE, $50 \mathrm{ml}$ ) was heated under reflux for the appropriate reaction time. At the end of the reaction period, the bulk sample was filtered and the catalyst was washed with DCE $(3 \times 30$ $\mathrm{ml})$. The solution was concentrated under reduced pressure and then made up to $50 \mathrm{ml}$ with DCE in the presence of tetradecane $(0.100 \mathrm{~g})$ as an internal standard. The mixture was analysed by gas chromatography and the yields of all identified components were calculated.

\section{$3 \quad$ Results and Discussion}

Initially, we investigated the nitration of phenol $(1 ; 9.5 \mathrm{mmol})$ (Scheme 1), over the zeolite $\mathrm{H} \beta$ (HBEA, Si/Al = 12.5; $2 \mathrm{~g}$ ) in DCE $(50 \mathrm{ml})$ under reflux conditions for $48 \mathrm{~h}$. The combined yield of nitrophenols 2 and $\mathbf{3}$ was $60 \%$ and the $2 / 3$ ratio was 1.0 . The GC trace also showed another product, which was identified as iso-propoxybenzene (4), but in only low yield (2\%). The total amount of material identified accounted for only $62 \%$ of the substrate used, but the weight of the total product obtained after removal of the solvent corresponded very closely to the amount calculated from the GC results, indicating that there were no further products that did not show up in the GC analysis. Destruction of the zeolite with 
hydrofluoric acid revealed that there was no product trapped within the pores of the zeolite. Further investigation suggested that some material was lost from the reaction mixture by evaporation during the reaction. This was confirmed by carrying out the reaction in an autoclave under otherwise identical conditions, which gave nitrophenols $\mathbf{2}$ and $\mathbf{3}$ in $94 \%$ yield with a $2 / 3$ ratio of 1.0 , along with $4 \%$ of 4 . Tests showed that the main component to be lost was phenol and that any small losses of products did not affect the proportions significantly. Therefore, for subsequent studies it was reasonable to use normal reflux apparatus, which was more convenient. The observed yields would inevitably total less than $100 \%$, but the proportions of products would be meaningful and if the research were to lead to reactions useful on a synthetic scale, unlike in the small analytical scale reactions used here, the losses through evaporation during reaction would be of negligible proportions.

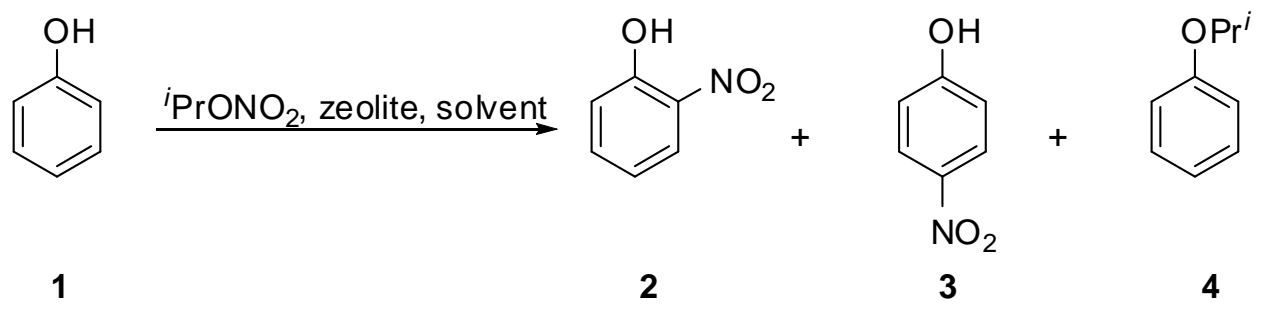

\section{Scheme 1}

In order to test the effect of the solid catalyst in this process, a number of different acidic zeolites ( $2 \mathrm{~g}$ for $9.5 \mathrm{mmol}$ of $\mathbf{1}$ ) was screened for efficacy in the reaction under the same conditions in a standard reflux apparatus. The results obtained are recorded in Table 1. 
Table 1 Nitration of phenol (1) over various zeolite catalysts according to Scheme $1^{\mathrm{a}}$

\begin{tabular}{|c|c|c|c|c|}
\hline \multirow[t]{2}{*}{ Catalyst (Si/Al ratio) } & \multicolumn{4}{|c|}{ Yields $(\%)^{\mathrm{b}}$} \\
\hline & 1 & 2 & 3 & 4 \\
\hline No catalyst & 56 & - & - & - \\
\hline $\mathrm{H} \beta(12.5)$ & - & 30 & 30 & 2 \\
\hline$H \beta(150)$ & 21 & 40 & 22 & 5 \\
\hline$H \beta(300)$ & 23 & 34 & 16 & 4 \\
\hline HY (5.1) & 21 & 33 & 19 & 3 \\
\hline HY (30) & 23 & 34 & 18 & 5 \\
\hline H-Mordenite (20) & 64 & 20 & 8 & 1 \\
\hline H-Mordenite (90) & 29 & 40 & 13 & 1 \\
\hline HZSM-5 (30) & 31 & 28 & 27 & - \\
\hline HZMS-5 (50) & 47 & 19 & 15 & - \\
\hline
\end{tabular}

${ }^{\mathrm{a}}$ A mixture of zeolite $(2 \mathrm{~g})$, phenol $(\mathbf{1} ; 0.90 \mathrm{~g}, 9.5 \mathrm{mmol})$ and iso-propyl nitrate $(2.00 \mathrm{~g}, 19.0$ $\mathrm{mmol})$ in DCE $(50 \mathrm{ml})$ was refluxed for $48 \mathrm{~h}$.

${ }^{\mathrm{b}}$ Yields calculated by quantitative GC using tetradecane as an internal standard.

In the absence of any catalyst, no reaction occurred. However, all types of zeolites tried catalysed the reaction. The reaction was complete (i.e. no phenol remaining) only when the large pore zeolite $\mathrm{H} \beta(\mathrm{Si} / \mathrm{Al}=12.5)$ was used as the catalyst. Other $\mathrm{H} \beta$ catalysts with higher Si/Al ratio (150 or 300) gave nitrophenols 2 and $\mathbf{3}$ in comparable or lower yield (50$62 \%$ ) and with a higher $\mathbf{2 / 3}$ ratio (ca. 1.8 and 2.1, respectively), along with unreacted phenol (1; 21-23\%), suggesting that sites that are more highly acidic (as present in the samples with higher $\mathrm{Si} / \mathrm{Al}$ ratios) favour ortho- product formation, but that the availability of fewer numbers of acidic sites causes some slowing down of the reaction. Zeolite HY behaved in a manner comparable to $\mathrm{H} \beta(\mathrm{Si} / \mathrm{Al}=300)$, while $\mathrm{H}-$ Mordenite, a large pore zeolite with a more restrictive channel structure, gave an even higher predominance of $\mathbf{2}$ over $\mathbf{3}$ ( $2 / \mathbf{3}$ ratio 3.1 for the sample with $\mathrm{Si} / \mathrm{Al}$ ratio $=90$ ). However, HZSM-5, a medium pore zeolite, resulted in a lower $\mathbf{2} / 3$ ratio of around. $1.0-1.3$, and rather low yields of nitrophenols (34-55\%). As a result of these findings, zeolite $\mathrm{H} \beta(\mathrm{Si} / \mathrm{Al}=12.5)$ was selected for further study.

In order to test the effect of the solvent in such reactions (Scheme 1), several reactions were carried out over zeolite $\mathrm{H} \beta(\mathrm{Si} / \mathrm{Al}=12.5)$, under identical conditions except for the 
nature of the solvent and the reflux temperature at which the reaction was therefore conducted. The results obtained are recorded in Table 2 .

Table 2 Nitration of phenol (1) according to Scheme 1 over zeolite $\mathrm{H} \beta$ ( $\mathrm{Si} / \mathrm{Al}=12.5)$ in different refluxing solvents ${ }^{\mathrm{a}}$

\begin{tabular}{|c|c|c|c|c|c|}
\hline \multirow[t]{2}{*}{ Solvent } & \multirow{2}{*}{$\begin{array}{l}\text { Reflux temperature } \\
\left({ }^{\circ} \mathrm{C}\right)\end{array}$} & \multicolumn{4}{|c|}{ Yields $(\%)^{\mathrm{b}}$} \\
\hline & & 1 & 2 & 3 & 4 \\
\hline Dichloromethane & 40 & 72 & 4 & 4 & 2 \\
\hline Chloroform & 61 & 62 & 13 & 15 & 2 \\
\hline 1,2-Dichloroethane & 83 & - & 30 & 30 & 2 \\
\hline Tetrachloroethylene & 121 & - & 34 & 30 & - \\
\hline Acetone & 56 & 89 & 5 & - & 一 \\
\hline Acetonitrile & 82 & 80 & 8 & 4 & - \\
\hline
\end{tabular}

${ }^{\mathrm{a}}$ A mixture of $\mathrm{H} \beta(\mathrm{Si} / \mathrm{Al}=12.5 ; 2 \mathrm{~g})$, phenol $(\mathbf{1} ; 0.90 \mathrm{~g}, 9.5 \mathrm{mmol})$ and iso-propyl nitrate $(2.00 \mathrm{~g}, 19.0 \mathrm{mmol})$ in solvent $(50 \mathrm{ml})$ was refluxed for $48 \mathrm{~h}$.

${ }^{\mathrm{b}}$ Yields calculated by quantitative GC using tetradecane as an internal standard.

The results suggested that within the group of chlorinated hydrocarbon solvents reflux temperature was the major factor influencing the reaction. The yields of nitrophenols $\mathbf{2}$ and $\mathbf{3}$ were highest when the reaction was carried out in the higher boiling solvents DCE or tetrachloroethylene and lowest in low-boiling dichloromethane, but the 2/3 ratio remained approximately constant at around 1 for all such solvents. By contrast, at comparable temperatures, reactions in the polar solvents were much slower, leading to lower yields, and much more selective towards the ortho-isomer. In order to separate the effects of solvent nature from those of temperature for reactions in chlorinated hydrocarbon solvents, reactions in several such solvents were conducted at a range of temperatures, controlled by the temperature of the heating bath in which the reaction vessel was placed. The results are presented in Table 3. 
Table 3 Nitration of phenol (1) in various solvents at different temperatures ${ }^{\mathrm{a}}$

\begin{tabular}{llllll}
\hline Solvent & Heating bath & \multicolumn{3}{l}{ Yields $(\%)^{\mathrm{b}}$} & \\
\cline { 3 - 6 } & Temperature $\left({ }^{\circ} \mathrm{C}\right)$ & $\mathbf{1}$ & $\mathbf{2}$ & $\mathbf{3}$ & $\mathbf{4}$ \\
\hline Dichloromethane & 20 & 97 & - & - & - \\
1,2-Dichloroethane & 20 & 97 & - & - & - \\
Tetrachloroethylene & 20 & 81 & 2 & - & - \\
1,2-Dichloroethane & 45 & 68 & 4 & - & 3 \\
Tetrachloroethylene & 45 & 77 & 3 & 3 & - \\
Dichloromethane & $65^{\mathrm{c}}$ & 52 & 10 & 5 & - \\
1,2-Dichloroethane & 65 & 52 & 10 & 5 & 3 \\
Tetrachloroethylene & 65 & 64 & 7 & 4 & 3 \\
1,2-Dichloroethane & 80 & 34 & 16 & 14 & 2 \\
1,2-Dichloroethane & $95^{\mathrm{c}}$ & - & 30 & 30 & 2 \\
Tetrachloroethylene & 95 & - & 34 & 32 & 3 \\
Tetrachloroethylene & $130^{\mathrm{c}}$ & - & 34 & 30 & - \\
\hline
\end{tabular}

${ }^{\mathrm{a}}$ A mixture of $\mathrm{H} \beta(\mathrm{Si} / \mathrm{Al}=12.5 ; 2 \mathrm{~g})$, phenol $(\mathbf{1} ; 0.90 \mathrm{~g}, 9.5 \mathrm{mmol})$ and iso-propyl nitrate $(2.00 \mathrm{~g}, 19.0 \mathrm{mmol})$ in solvent $(50 \mathrm{ml})$ was stirred $48 \mathrm{~h}$ at the set temperature.

${ }^{\mathrm{b}}$ Yields calculated by quantitative GC using tetradecane as an internal standard.

${ }^{\mathrm{c}}$ Bath temperature above reflux temperature of solvent, but reaction temperature lower.

The product profiles obtained at any given bath temperature were similar for all three solvents, indicating that reaction temperature was a more important variable than the rather small differences in the properties of the different chlorinated hydrocarbon solvents. Interestingly, reactions conducted at lower temperatures generally showed greater selectivity towards the ortho-isomer 2 than ones conducted at elevated temperatures. For subsequent experiments it was appropriate to use refluxing DCE as the solvent of choice.

In order to check whether the standard period of 48 hours used in reactions thus far was actually required for reactions in refluxing DCE, a series of reactions was conducted over various reaction times. The results obtained are recorded in Table 4, which showed that a reaction period of 48 hours was needed for the reaction to go to completion. The reactions conducted for shorter periods appeared to give slightly greater selectivity for the orthoisomer than ones conducted over longer periods. 
Table 4 Nitration of phenol (1) in refluxing DCE for various reaction times ${ }^{\mathrm{a}}$

\begin{tabular}{|c|c|c|c|c|}
\hline \multirow[t]{2}{*}{ Reaction Time (h) } & \multicolumn{4}{|c|}{ Yields $(\%)^{b}$} \\
\hline & 1 & 2 & 3 & 4 \\
\hline 6 & 42 & 19 & 15 & 2 \\
\hline 12 & 31 & 20 & 19 & 3 \\
\hline 24 & 14 & 24 & 24 & 3 \\
\hline 36 & 10 & 25 & 25 & 3 \\
\hline 48 & - & 30 & 30 & 2 \\
\hline
\end{tabular}

${ }^{\text {a }}$ A mixture of $\mathrm{H} \beta(\mathrm{Si} / \mathrm{Al}=12.5 ; 2 \mathrm{~g})$, phenol $(\mathbf{1} ; 0.90 \mathrm{~g}, 9.5 \mathrm{mmol})$ and iso-propyl nitrate $(2.00 \mathrm{~g}, 19.0 \mathrm{mmol})$ in DCE $(50 \mathrm{ml})$ was refluxed for the appropriate reaction time.

${ }^{\mathrm{b}}$ Yields calculated by quantitative GC using tetradecane as an internal standard.

We next investigated the effect of concentration on the reaction by conducting reactions in different amounts of DCE. The results (Table 5) show that reaction was complete (no phenol remaining) in up to $60 \mathrm{ml}$ of DCE but was not yet complete after 48 hours in more dilute conditions. Mass balances generally improved with increased dilution, consistent with lower losses by evaporation of phenol from more dilute solutions. Subject to experimental error limits, it appeared that the proportion of the para- isomer went through a maximum in the middle of the range of concentrations tried, although the differences were not large.

Table 5 Nitration of phenol (1) according to Scheme 1 at various concentrations ${ }^{\mathrm{a}}$

\begin{tabular}{llllll}
\hline 1,2-Dichloroethane $(\mathrm{ml})$ & \multicolumn{3}{l}{${\text { Yields }(\%)^{\mathrm{b}}}^{\mathrm{b}}$} & Mass balance $(\%)^{\mathrm{c}}$ \\
\cline { 2 - 5 } & $\mathbf{1}$ & $\mathbf{2}$ & $\mathbf{3}$ & $\mathbf{4}$ & \\
\hline 20 & - & 28 & 24 & 1 & 53 \\
30 & - & 30 & 25 & 4 & 59 \\
40 & - & 26 & 25 & 4 & 55 \\
50 & - & 30 & 30 & 2 & 62 \\
60 & - & 30 & 31 & 2 & 63 \\
70 & 13 & 27 & 20 & 4 & 64 \\
80 & 12 & 27 & 20 & 4 & 63 \\
100 & 15 & 31 & 27 & 1 & 74 \\
\hline
\end{tabular}

${ }^{\mathrm{a}}$ A mixture of $\mathrm{H} \beta(\mathrm{Si} / \mathrm{Al}=12.5 ; 2 \mathrm{~g})$, phenol $(\mathbf{1} ; 0.90 \mathrm{~g}, 9.5 \mathrm{mmol})$ and iso-propyl nitrate $(2.00 \mathrm{~g}, 19.0 \mathrm{mmol})$ in various quantities of DCE was refluxed for $48 \mathrm{~h}$.

${ }^{\mathrm{b}}$ Yields calculated by quantitative GC using tetradecane as an internal standard.

${ }^{c}$ Sum of yields of identified products as calculated by quantitative GC. 
Finally, the effects of the quantities of catalyst $(\mathrm{H} \beta, \mathrm{Si} / \mathrm{Al}=12.5)$ and reagent (isopropyl nitrate) were investigated and the results are shown in Tables 6 and 7, respectively. It is clear from the results in Table 6 that the amount of catalyst affects the rate of the reaction but does not substantially affect the selectivity. Similarly, the rate increases as more reagent is used, resulting in a trend to higher product yields and higher recorded mass balances (because the phenol is removed more quickly from the mixture by reaction) at higher reagent concentrations. However, there is again little effect on product proportions and at the highest reagent concentration a small amount of 2,4-dinitrophenol was also detected.

Table 6 Nitration of phenol (1) over various quantities of zeolite $\mathrm{H} \beta^{\mathrm{a}}$

\begin{tabular}{lllll}
\hline $\mathrm{H} \beta(\mathrm{Si} / \mathrm{Al} ; \mathrm{g})$ & \multicolumn{2}{l}{ Yields $(\%)^{\mathrm{b}}$} & $\mathbf{3}$ & $\mathbf{4}$ \\
\cline { 2 - 5 } & $\mathbf{1}$ & $\mathbf{2}$ & 12 & 3 \\
0.5 & 43 & 17 & 23 & 3 \\
1.0 & 22 & 23 & 30 & 2 \\
2.0 & - & 30 & 30 & 2 \\
3.0 & - & 32 & \\
\hline
\end{tabular}

${ }^{\mathrm{a}}$ A mixture of $\mathrm{H} \beta(\mathrm{Si} / \mathrm{Al}=12.5)$, phenol $(\mathbf{1} ; 0.90 \mathrm{~g}, 9.5 \mathrm{mmol})$ and iso-propyl nitrate $(2.00 \mathrm{~g}$, $19.0 \mathrm{mmol})$ in DCE $(50 \mathrm{ml})$ was refluxed for $48 \mathrm{~h}$.

${ }^{\mathrm{b}}$ Yields calculated by quantitative GC using tetradecane as an internal standard.

Table $7 \quad$ Nitration of phenol (1) with various quantities of $i s o$-propyl nitrate ${ }^{\mathrm{a}}$

\begin{tabular}{|c|c|c|c|c|c|}
\hline \multirow[t]{2}{*}{ iso-Propyl nitrate (mmol) } & \multicolumn{4}{|c|}{${\text { Yields }(\%)^{b}}^{b}$} & \multirow[t]{2}{*}{ Mass balance $(\%)^{\mathrm{c}}$} \\
\hline & 1 & 2 & 3 & 4 & \\
\hline 9.5 & 15 & 22 & 13 & 2 & 52 \\
\hline 14.0 & 11 & 27 & 24 & 1 & 63 \\
\hline 19.0 & - & 27 & 27 & 2 & 56 \\
\hline 28.5 & - & 39 & 30 & 4 & 73 \\
\hline 38 & - & 37 & 22 & 3 & $71^{\mathrm{d}}$ \\
\hline
\end{tabular}

${ }^{\text {a }}$ A mixture of $\mathrm{H} \beta(\mathrm{Si} / \mathrm{Al}=12.5 ; 2 \mathrm{~g})$, phenol $(\mathbf{1} ; 0.90 \mathrm{~g}, 9.5 \mathrm{mmol})$ and various quantities of iso-propyl nitrate in DCE $(50 \mathrm{ml})$ was refluxed for $48 \mathrm{~h}$.

${ }^{\mathrm{b}}$ Yields calculated by quantitative GC using tetradecane as an internal standard.

${ }^{\mathrm{c}}$ Sum of yields of identified products as calculated by quantitative GC.

${ }^{\mathrm{d}}$ Includes $9 \%$ of 2,4-dinitrophenol also identified in the product mixture. 


\section{Conclusions}

Proton forms of several zeolites are able to catalyse the reaction of phenol with iso-propyl nitrate, which does not take place in the absence of a catalyst. Zeolite $\mathrm{H} \beta$ with a Si/Al ratio of 12.5 was the most active of the catalysts tried and also gave the highest proportion of paranitrophenol, but the ortho/para ratio was still only around 1:1. Mononitrophenols are formed in high yields (almost quantitative if steps are taken to prevent evaporation of phenol from the reaction vessel) when reactions are carried out over two days in refluxing DCE. The slow step is probably formation of an active nitrating species, which then probably reacts rather indiscriminately at the relatively high temperatures employed, leading to the low selectivities observed.

Acknowledgments We thank Cardiff University and the Saudi Government for financial support.

\section{References}

[1] K. Schofield, Aromatic Nitration (Cambridge University Press, Cambridge, 1980).

[2] G.A. Olah, R. Malhotra and S.C. Narang, Nitration: Methods and Mechanisms (VCH, New York, 1989).

[3] R.G. Coombes, J.G. Golding and P. Hadjigeorgiou, J. Chem. Soc., Perkin Trans. 2 (1979) 1451.

[4] J.H. Clark, Acc. Chem. Res. 35 (2002) 791.

[5] Catalysis of Organic Reactions using Supported Inorganic Reagents, ed. J.H. Clark (VCH, New York, 1994).

[6] L. Delaude, P. Laszlo and K. Smith, Acc. Chem. Res. 26 (1993) 607. 
[7] K. Smith, In: New Aspects of Organic Synthesis II, eds. Z. Yoshida and Y. Ohshiro (Kadonsha, Tokyo and VCH, Weinheim, 1992), p. 43.

[8] M. Butters, In: Solid Supports and Catalysts in Organic Synthesis, ed. K. Smith, (Ellis Horwood, Chichester, 1992) p. 130.

[9] K. Smith, In: Catalysis of Organic Reactions, ed. M.G. Scaros and M.L. Prunier (Marcel Dekker, New York, 1991) p. 91.

[10] K. Smith and G.A. El-Hiti, Curr. Org. Synth. 1 (2004) 253.

[11] K. Smith and G.A. El-Hiti, Curr. Org. Chem. 10 (2006) 1603.

[12] K. Smith, S.D. Roberts and G.A. El-Hiti, Org. Biomol. Chem. 1 (2003) 1552.

[13] K. Smith, G.A. El-Hiti, A.J. Jayne and M. Butters, Org. Biomol. Chem. 1 (2003) 1560.

[14] K. Smith, G.A. El-Hiti, A.J. Jayne and M. Butters, Org. Biomol. Chem. 1 (2003) 2321.

[15] K. Smith, G.M. Ewart, G.A. El-Hiti and K.R. Randles, Org. Biomol. Chem. 2 (2004) 3150.

[16] K. Smith, G.A. El-Hiti, M.E.W. Hammond, D. Bahzad, Z. Li and C. Siquet, J. Chem. Soc., Perkin Trans. 1 (2000) 2745.

[17] K. Smith, M. Butters, W.E. Paget, D. Goubet, E. Fromentin and B. Nay, Green Chem. $1(1999) 83$.

[18] K. Smith, A. Musson and G.A. DeBoos, J. Org. Chem. 63 (1998) 8448.

[19] K. Smith, T. Gibbins, R.W. Millar and R.P. Claridge, J. Chem. Soc., Perkin Trans. 1 (2000) 2753.

[20] K. Smith, S. Almeer and S.J. Black, Chem. Commun. (2000) 1571.

[21] K. Smith, S. Almeer and C. Peters, Chem. Commun. (2001) 2748.

[22] K. Smith, S. Almeer, S.J. Black and C. Peters, J. Mater. Chem. 12 (2002) 3285. 
[23] J.A.R. Rodrigues, A.P. de Oliveira Filho, P.J.S. Moran and R. Custódio, Tetrahedron 55 (1999) 6733.

[24] W.-P. Yin and M. Shi, Tetrahedron 61 (2005) 10861; B. Gigante, A.O. Prazeres, M.J. Marcelo-Curto, A. Cornélis and P. Laszlo, J. Org. Chem. 60 (1995) 3445; and references cited therein.

[25] T. Milczak, J. Jacniacki, J. Zawadzki, M. Malesa and W. Skupiński, Synth. Commun. $31(2001) 173$.

[26] M.M. Heravi, T. Benmorad, K. Bakhtiari, F.F. Bamoharram and H.H. Oskooie, J. Mol. Catal. A: Chem. 264 (2007) 318; S. Mallick and K.M. Parida, Catal. Commun. 8 (2007) 1487.

[27] K.M. Parida and D. Rath, J. Mol. Catal. A: Chem. 258 (2006) 381.

[28] J.M. Riego, Z. Sedin, J.-M. Zaldlvar, N.C. Marzianot and C. Tortato, Tetrahedron Lett. 37 (1996) 513.

[29] M.A. Zolfigol, E. Ghaemi and E. Madrakian, Molecules 6 (2001) 614.

[30] K.R. Sunajadevi and S. Sugunan, Catal. Commun. 6 (2005) 611; Mater. Lett. 60 (2006) 3813.

[31] A.S. Khder and A.I. Ahmed, Appl. Catal., A (2009) in press; doi:10.1016/j.apcata.2008.11.030, available online pre-publication.

[32] S.P. Dagade, V.S. Kadam and M.K. Dongare, Catal. Commun. 3 (2002) 67.

[33] T. Esakkidurai and K. Pitchumani, J. Mol. Catal. A: Chem. 185 (2002) 305.

[34] R. Taylor, Electrophilic Aromatic Substitution (Wiley, Chichester, 1990), p. 263; D. Vione, S. Belmondo and L. Carnino, Environ. Chem. Lett. 2 (2004) 135. 